\title{
Climate Change Adaptation and Resilience through Big Data
}

\author{
Md Nazirul Islam Sarker ${ }^{1}$, Bo Yang ${ }^{2 *}$, Yang Lv ${ }^{3}, \mathrm{Md}_{\text {Enamul Huq }}^{4}$, M M Kamruzzaman ${ }^{5}$ \\ School of Political Science and Public Administration, Neijiang Normal University, Neijiang, China ${ }^{1}$ \\ Sichuan Radio and TV University, Chengdu, China ${ }^{2}$ \\ School of Public Administration, Sichuan University, Chengdu, China ${ }^{2,3}$ \\ State Key Laboratory of Information Engineering in Surveying, Mapping \& Remote Sensing, Wuhan University, Wuhan, China ${ }^{4}$ \\ Department of Computer and Information Science, Jouf University, Sakaka, Al-Jouf, KSA ${ }^{5}$
}

\begin{abstract}
The adverse effect of climate change is gradually increasing all over the world and developing countries are more sufferer. The potential of big data can be an effective tool to make an appropriate adaptation strategy and enhance the resilience of the people. This study aims to explore the potential of big data for taking proper strategy against climate change effects as well as enhance people's resilience in the face of the adverse effect of climate change. A systematic literature review has been conducted in the last ten years of existing kinds of literature. This study argues that resilience is a process of bounce back to the previous condition after facing any adverse effect. It also focuses on the integrated function of the adaptive, absorptive and transformative capacity of a social unit such as individual, community or state for facing any natural disaster. Big data technologies have the capacity to show the information regarding upcoming issues, current issues and recovery stages of the adverse effect of climate change. The findings of this study will enable policymakers and related stakeholders to take appropriate adaptation strategies for enhancing the resilience of the people of the affected areas.
\end{abstract}

Keywords-Disaster resilience; administrative resilience; community resilience; disaster management; environmental management

\section{INTRODUCTION}

Climate change is considered as a global challenge. The developing countries are facing increasing vulnerability due to global climate change. A long-term technology-driven approach is necessary to reduce vulnerability and disaster risk. Since the nature of global climate change is very complex, it requires a context-specific innovative approach to develop the adaptive, absorptive and transformative capacity of the social system. The enhanced capacities of a social unit make itself resilient against the adverse effect of climate change [1]. The adaptation strategy of vulnerable communities cannot help properly from huge direct and indirect damages of natural disasters as it is due to climate change [2]. It is now well established that technology can help to handle the situation of natural disasters. Technology can help to develop a strategy for disaster management from early warning about the disaster to post-disaster management. In every step of disaster management, policymakers, leaders, researchers, and administrators can use technology for managing the adverse effect of climate change.
The word 'resilience' originates from Latin word resilio that means 'to jump back'. Walker and Salt [3] have claimed that 'resilience' originated from ecological research where Holling [4] sought to differentiate between an ecological system that persists in a condition of equilibrium or stability, and response of dynamic systems when they are stressed and move from this equilibrium. A resiliency perspective is an understanding of a system's adaptive capacity [5]. Disaster management is an integrated process of preparedness, response, recovery and mitigation. All the four processes are tools of enhancing adaptive, absorptive and transformative capacity of an individual, group or community and ensure resilience. Resilience is a holistic concept that enables a social unit to bounce back from the affected condition to the previous normal condition after facing any stress caused by climate change [6]. It also focuses on an integration of adaptive, absorptive and transformative capacity. Resilience actually focuses on the multi-dimensional capacity of a social unit to face disasters and successfully manage it through reducing vulnerability and enhancing capacities [7]. Resilience also can address all the root causes of disasters through context-based adaptation strategy. It actually focuses on the way of capacity building of people so that people can reduce vulnerability, potential threat, stress, challenges and risk related to natural disasters. Big data technology can help to enhance climate resilience by context specific policy making, administration, research and leadership [8].

As a new paradigm, a big data approach is considered as the most effective method for taking quick and effective decisions [9]. It can analyze the huge amount of data obtained from various sources such as weather data, social media, electronic and print media, non-governmental organizations, voluntary community organizations, and various social networking sites. Big data provides a big opportunity for communication which can help susceptible community people about an upcoming threat, challenges, risks and disasters [10]. Communication provides a way to communicate with each other before, during and after a disaster to inform the condition to one another and make preparation and also acts as a source of big data [11]. Big data encourage researchers and policymakers to conduct an in-depth analysis of communication data from a mobile phone, social media and other communication devices which has big rationality for disaster resilience.

\footnotetext{
*Corresponding Author
} 
Many pieces of research have already been done on climate change impacts [12,13] disaster management [14], disaster resilience $[8,10]$, and big data application in the environmental management field [10-12] but the potential of big data for climate resilience is still lacking. Since climate change causes natural disasters, vulnerability, and scarcity of natural resources, so big data can be an effective approach to enhance climate resilience. Frequent natural disasters are also the effect of rapidly changing climatic conditions. A big datadriven effective strategy can be helpful to increase resilience. Therefore, this study aims to explore the potential of big data for enhancing climate resilience.

\section{Methodology}

This study is based on a qualitative approach, particularly the desk literature review. A systematic literature review has been done on the assessment of the last 10 years of literature. Recent data has been collected for participating in the ongoing debate on the potential of big data for climate resilience. This study mainly considers the big data approaches which have a potential contribution to enhancing climate resilience. A desk literature review is considered an indispensable part of developing a new paradigm of a potential field. Therefore, recent related data has been searched extensively in popular databases like the web of science, Engineering village, and Scopus. Many keywords such as 'climate change, resilience, disaster, vulnerability, adaptive, absorptive and transformative capacity, big data, and disaster management have been used. The data collection has been done from October to November 2019. The desk review has guided by certain criteria such as (a) is this study focuses on big data for climate resilience? (b) Is this study articulate climate change adaptation using big data approaches? and (c) Is full text of this study available? Certain exclusion criteria have also been followed such as articles other than English language, duplication and article having a similar concept.

\section{RESULTS}

\section{A. Systematic Analysis Results}

Qualitative document selection has been done by following the guidelines of Systematic Review and MetaAnalysis (PRISMA) [17]. PRISMA approach comprises four stages for quality document selection such as identification, screening, eligibility and included. After searching the renowned databases, this study obtained 529 documents from the main search with other 5 documents from the reference list. In the screening stage, 397 documents have been removed after the abstract screening. Similarly, in the eligibility stage, 109 documents have been removed due to the non-availability of the full text, non-relevancy, and documents not focusing on big data and climate resilience properly. Finally, most relevant 28 documents have been considered for in-depth analysis comprising journal articles, books, book chapters, and working papers (Fig. 1).

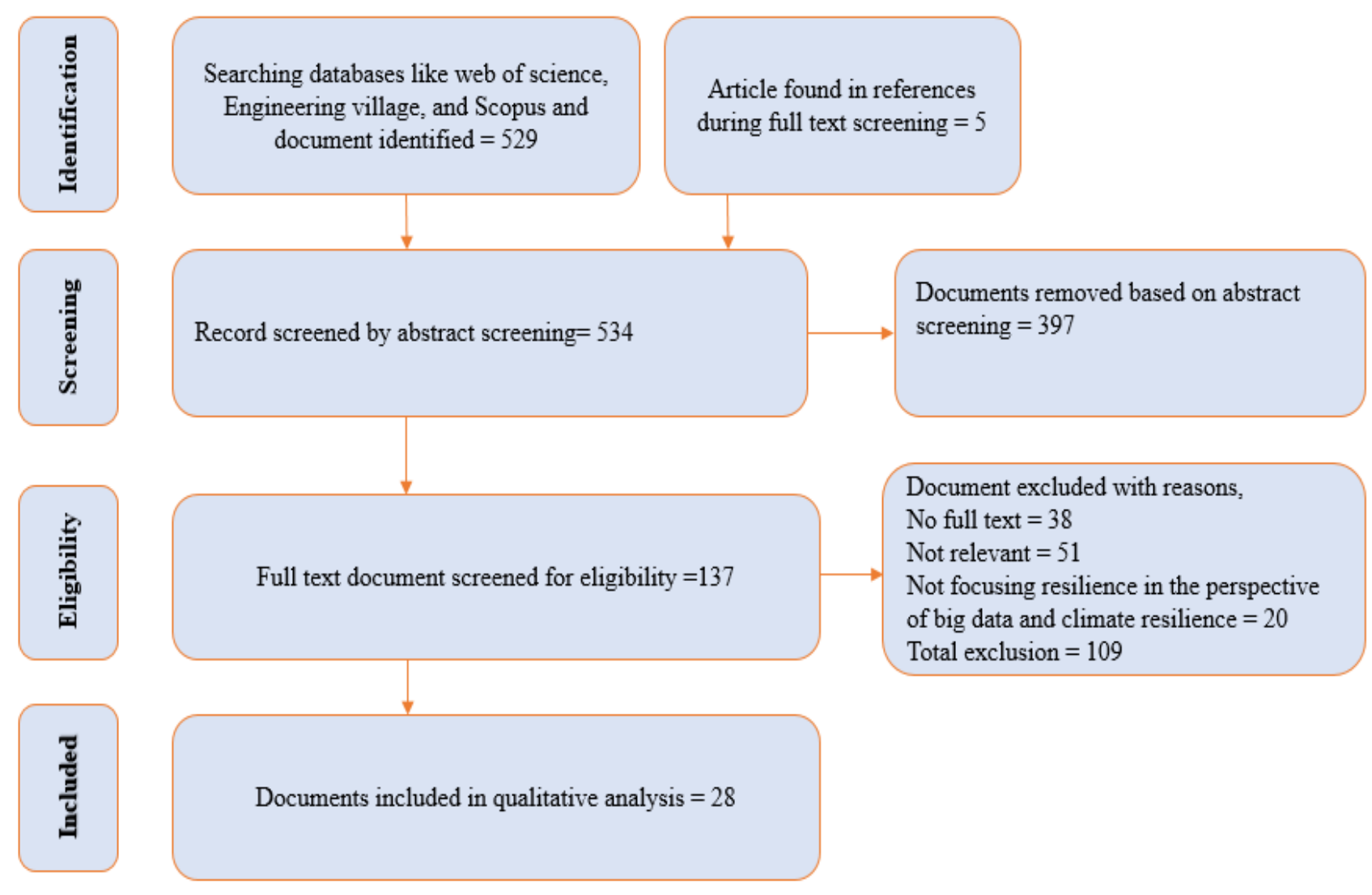

Fig 1. PRISMA Flow Diagram of Document Selection. 


\section{B. Analytical Results}

a) Sources of Big Data: This study is analyzed more relevant 28 documents and revealed the potential sources of big data. The major sources of big data are satellite imagery, aerial imagery and videos, wireless sensor web network, Light Detection and Ranging (LiDAR), simulation data, spatial data, crowdsourcing, social media and mobile GPS, and call record. The characteristics and recommended sources of big data are presented in Table I.

b) Recommended Phases of Disaster Management: The majority of the researchers suggested four main steps of disaster management and climate change resilience such as preparedness, mitigation, response and recovery that can directly use big data technologies for managing a disaster. This study considers all the possible climate change adaptation technologies that can help to enhance resilience of the affected people. Besides, most of the studies also suggested some subcomponents of disaster management and resilience which provides an opportunity to use big data technologies at the proper time and places (Table II).

TABLE I. SOURCES OF BIG DATA

\begin{tabular}{|c|c|c|}
\hline Sources of big data & Characteristics & References \\
\hline Satellite imagery & $\begin{array}{l}\text { High resolution, multi- } \\
\text { technical and dimensional } \\
\text { imagery } \\
\text { Land use system, water } \\
\text { bodies, direction and } \\
\text { damaged items }\end{array}$ & $\begin{array}{l}\text { Qadir et al. [18] } \\
\text { Tomaszewski et al. } \\
\text { [19] } \\
\text { Park \& Johnston [20] }\end{array}$ \\
\hline $\begin{array}{l}\text { Aerial imagery and } \\
\text { videos }\end{array}$ & $\begin{array}{l}\text { Unnamed aerial vehicles } \\
\text { Spatial resolution of image } \\
\text { Various sensors such as } \\
\text { camera, infrared, ultra- } \\
\text { violet, radiation and } \\
\text { weather sensors }\end{array}$ & $\begin{array}{l}\text { Yu et al. [16] } \\
\text { Anbarasan et al. [21] }\end{array}$ \\
\hline $\begin{array}{l}\text { Wireless sensor web } \\
\text { network }\end{array}$ & $\begin{array}{l}\text { Increase response time and } \\
\text { success delivery, reducing } \\
\text { the latency } \\
\text { Effective communication }\end{array}$ & $\begin{array}{l}\text { Adeel et al. [22] } \\
\text { Ogie et al. (Ogie et } \\
\text { al. 2019) } \\
\text { Ha [24] }\end{array}$ \\
\hline $\begin{array}{l}\text { Light Detection and } \\
\text { Ranging (LiDAR) }\end{array}$ & $\begin{array}{l}\text { Exact ground condition } \\
\text { Authentic and reliable } \\
\text { source } \\
\text { Detect structural damages }\end{array}$ & $\begin{array}{l}\text { Yu et al.[16] } \\
\text { Shan et al. [25] } \\
\text { Carley et al. [26] }\end{array}$ \\
\hline Simulation data & $\begin{array}{l}\text { Effective prediction } \\
\text { Meteorological and land } \\
\text { surface phenomena } \\
\text { Agent-based modeling }\end{array}$ & $\begin{array}{l}\text { Hyslop [27] } \\
\text { Carley et al. [26] }\end{array}$ \\
\hline Spatial data & $\begin{array}{l}\text { Geographic information } \\
\text { system (GIS) } \\
\text { Vulnerability assessment } \\
\text { and prediction }\end{array}$ & $\begin{array}{l}\text { Tomaszewski et al. } \\
\text { [19] }\end{array}$ \\
\hline Crowdsourcing & $\begin{array}{l}\text { Online platform } \\
\text { Real time data }\end{array}$ & $\begin{array}{l}\text { Ogie et al. [23] } \\
\text { Clark \& Guiffault } \\
{[29]} \\
\end{array}$ \\
\hline Social Media & $\begin{array}{l}\text { Multi-dimensional } \\
\text { communication tool } \\
\text { Real time data } \\
\text { Support all phases of } \\
\text { disaster management }\end{array}$ & $\begin{array}{l}\text { Resnyansky [30] } \\
\text { Schemp et al.[31] } \\
\text { Enenkel et al. [35] }\end{array}$ \\
\hline $\begin{array}{l}\text { Mobile GPS and call } \\
\text { record }\end{array}$ & $\begin{array}{l}\text { Global Positioning System } \\
\text { (GPS) } \\
\text { Call detail records (CDR) }\end{array}$ & $\begin{array}{l}\text { Qadir et al.[18] } \\
\text { Gupta et al. [32] }\end{array}$ \\
\hline
\end{tabular}

TABLE II. PHASES OF DISASTER MANAGEMENT

\begin{tabular}{|c|c|c|}
\hline $\begin{array}{l}\text { Main } \\
\text { components }\end{array}$ & Available technology & References \\
\hline \multirow{2}{*}{ Preparedness } & $\begin{array}{l}\text { Remote sensing imagery } \\
\text { Social media data } \\
\text { Crowdsourced data }\end{array}$ & $\begin{array}{l}\text { Lv et al. [33] } \\
\text { Horita et al. [34] }\end{array}$ \\
\hline & $\begin{array}{l}\text { Remote sensing imagery (TRMM } \\
\text { rainfall, Radarsat SAR, and } \\
\text { Namibia Flood SensorWeb) } \\
\text { Social media data }\end{array}$ & $\begin{array}{l}\text { Enenke et al. [35] } \\
\text { Ragini et al. [10] }\end{array}$ \\
\hline \multirow[b]{2}{*}{ Mitigation } & $\begin{array}{l}\text { GIS } \\
\text { Moderate Resolution Imaging } \\
\text { Spectroradiometer (MODIS) } \\
\text { Crowdsourced data } \\
\text { Mobile Metadata } \\
\end{array}$ & $\begin{array}{l}\text { Tomaszewski et } \\
\text { al. [19] } \\
\text { Horita et al. [34] }\end{array}$ \\
\hline & $\begin{array}{l}\text { Remote sensing imagery } \\
\text { H212 model (Hurrican Weather } \\
\text { research and Forecasting) } \\
\text { FLOR model (Forecast Oriented } \\
\text { Low Ocean Resolution) } \\
\text { CYGNSS (Cyclone Global } \\
\text { Navigation Satellite System) } \\
\text { Airborne radar resolution } \\
\end{array}$ & $\begin{array}{l}\text { Goldenberg et al. } \\
\text { [36] } \\
\text { Masood et al. [37] }\end{array}$ \\
\hline \multirow[t]{2}{*}{ Response } & $\begin{array}{l}\text { Remote sensing imagery } \\
\text { GEN-CAN (Global Earth } \\
\text { Observation Catastrophe } \\
\text { Assessment Network) } \\
\text { Social media data }\end{array}$ & Enenkel et al. [35] \\
\hline & $\begin{array}{l}\text { Aerial adhoc networks } \\
\text { SUAVs (Small Unmanned Aerial } \\
\text { Vehicles) } \\
\text { Team Phone }\end{array}$ & $\begin{array}{l}\text { Felice et al. [38] } \\
\text { Lu et al. [39] }\end{array}$ \\
\hline Recovery & $\begin{array}{l}\text { Mobile Metadata } \\
\text { Remote sensing imagery } \\
\text { Quick bird imagery } \\
\text { Social media data }\end{array}$ & Contras et al. [40] \\
\hline
\end{tabular}

\section{DISCUSSION}

\section{A. Big Data Sources}

1) Satellite imagery: Satellite imagery provides quantitative and qualitative data for disaster management which can help to conduction management operation as well as risk reduction. It can be frequently used for assessing the condition of post-disaster [18]. The major contribution of remote sensing such as high resolution, multi-technical and dimensional imagery that provides support for planning pre and post-disaster assessment. Satellite imagery provides information about changing land-use systems, water bodies, direction and damaged items of the affected area [19]. This information can help to make proper decisions about rescue methods. It is not only providing general images but also three D-dimensional images with an attitude that can easily help to detect the affected areas and level of damages [16]. It also helps to identify damaged buildings and volumes of disasteraffected areas. Satellite imagery is considered one of the major methods for disaster management due to its usage on the reduction of risk related to flood, landslide and human settlement [20].

2) Aerial imagery and videos: Unnamed Aerial Vehicles (UAVs) have been used for capturing aerial image which can be played a vital role in creating situational awareness [16]. It 
is considered a better method than satellite imagery due to speed and spatial resolution of the image. It can be used as an advanced level tool for detecting fine cracks, damaged structure and the extent of damages. UAVs comprises a different kind of sensors such as camera, infrared, ultra-violet, radiation and weather sensors along with spectrum analyzers [21]. It is a tool that can supply useful information to transportation planning related to real-time and situational information. UAVs are considered as an authentic data source that can help to identify real damaged caused by disasters.

3) Wireless sensor web network: Technology related to wireless sensor web (WSW) can be used for easy warning systems which helps to take preparation for saving assets from natural disasters [22]. Situational awareness can be done by using WSW [23]. Integrated use of the WSW network can enhance response time, reducing the latency as well as increasing success delivery. These technologies also ensure a connection between the affected population and the rescue team. WSW based IoT technology provides better communication in the disaster affected areas where communication structure damaged by natural disasters [24].

4) Light Detection and Ranging (LiDAR): Exact ground conditions of disaster-affected areas can be easily detected by LiDAR by using an advanced elevation model [12]. Though it is a little bit time consuming and expensive, it provides authentic and reliable information. It explores the real condition by providing high resolution [23]. The ability of LiDAR is very helpful for geological, features and mapping. It is well recognized that LiDAR can provide accurate data for water and flood assessment as well as prediction of future flooding [13]. It also provides reliable information about structural damage as well as elevation changes by natural disasters.

5) Simulation data: A simulation is a key approach for prediction. Numerical simulation can be a good approach for predicting future natural disasters by analyzing meteorological and land surface phenomena as well as different kinds of pollutions [24]. It also provides 3D modeling that can help to predict probable damage of natural disasters. Generally, huge data is generated at the time of disasters. Disaster management requires proper production, verification, validation, and improvement of data for exploring real complexity caused by natural disasters [25]. Simulation data is also helpful for assessing environmental changes through agent-based modeling. An ecological model can provide realistic information about landslide by using simulation data [13].

6) Spatial data: Spatial data is helpful for disaster management especially for vulnerability assessment and prediction of natural hazards. Tomaszewski et al. [18] conducted a study on geographic information systems (GIS) and mentioned that GIS data such as FEMA, data feeds, World Bank data, national as well as open street map is helpful for disaster management. Spatial data is frequently used for disaster resilience in the developing countries.
7) Crowdsourcing: Crowdsourcing provides an opportunity to work a large number of people in an online platform for achieving a common goal. In disaster-related crowdsourcing, many affected people can share their idea, experience, and practices for disaster management [26]. In that platform, disaster victims can share real-time information. Though it is a good source for big data, it has still some challenges especially from the credibility of the data to decision making [17]. The collection, processing, and analysis of crowdsourced data require advanced tools because of its nature and volume. Crowdsourced data is also helpful for finding out the location of the disaster-affected area [27]. It is convinced to collect crowdsourced data by using a mobile and online platform.

8) Social media: Nowadays social media is playing a vital role in almost all aspects of life. It is one of the main big data sources. Social media is considered one of the top communication tools for disaster management information [26]. It provides a piece of multi-dimensional information regarding disaster events. Though social media has shortcomings due to its different kinds of data, it is still effective for disaster management [28]. Communication for disaster management was dealt with by participating organizations, victims and affected populations, vulnerable community and areas in the traditional model [29]. But big data-driven technologies can easily handle the issues very accurately and timely [41]. Since various disaster genres such as early warning, caution instruction, and immediate interaction are connected with disaster type, phases and causes, so technology-based communication can speed up the process of disaster management [30]. Various social media such as Facebook, Twitter, WhatsApp, IMO, WeChat and QQ have a great impact on almost all phases of disaster management. Social media can be used in various ways for disaster management. Social media data should be collected carefully and then process, analyze and decision making are necessary for disaster management [21]. Similarly, the decision about disaster can be easy spread-out using social media. Scholar recognized the importance of social media for disaster management phases and ensuring resilience.

9) Mobile based GPS and record of call data: The mobile phone acts as an important instrument in a disaster situation to contact family, relatives, and friends as well as to know the location for moving to a safe place. Integrated sensors of mobile phones help to identify the most affected peoples as well as the urgent needs of resources [17]. But sometimes natural disaster disrupts the electricity connection which causes an interruption of getting mobile phone services in disaster-affected places. Mobile-based GPS (Global Positioning System) is a vital way to collect mobile-based sensing data for the detection of people's behavior and movement at the time of natural disasters [18]. It helps to get real-time data of disasters regarding the human reaction to the effect of natural disasters as well as warning and evacuation process [12]. GPS helps to identify the location, altitude, 
magnitude and related issues of natural disasters. GPS is generally working based on three basic criteria such as proper location, comparative movement and real-time.

Call detail records (CDR) of mobile companies can record all the calls during disasters which provide a huge number of data that is real-time and need-based [42]. Disaster management personnel can easily use this big data to make quick decisions for ensuring immediate services to disasteraffected people [11]. Since the size of CDR data is large so big data approaches can take the opportunity to handle it. CDR tools can also collect the data related to human movement as well as behavior in the social network regarding natural disasters [43]. This approach can also collect the identity of the sender and receiver as well as the data of calling and SMS. From CDR data, concerned personnel can know the population density and size of the total population in the disaster-affected region [9]. Since all the subscriber are under the cellular network, it is useful to get accurate data by using this approach.

\section{B. Big Data Approach for Climate Resilience}

Vulnerability is an emerging concept across disciplines, useful in understanding and assessing the status of people's condition in the face of natural hazards. The major characteristics of climate change vulnerability are dynamic and influence people's social and biophysical processes and systems. Significant mobilization is necessary from the government, non-governmental organizations, researchers, and farmers to develop successful adaptation strategies [44]. The people of developing countries are vulnerable communities due to excessive dependency on agriculture and having a low income. However, these burdens may fuel the exploration of potential adaptive capacities of resource-poor communities [45]. The extent of people's susceptibility is increased due to the increasing vulnerability to natural hazards of almost all spheres of life, like the social, physical, human, financial, and natural dimensions [46]. Though the effect of natural hazards may be occasional, seasonal, or year-round, the extent of exposure is not the same for all communities.

1) Preparedness: The damage to climate change be can be reduced by effective detection and monitoring. Remote sensing data is usually a big source of big data that helps to detect any abnormalities of weather and disaster probability. Satellite remote sensing also can be used for the detection of the adverse effect of climate change. Some natural disasters like flooding and fire can be monitored by remote sensing imagery that helps to take proper measures for mitigation. Early detection helps to provide basic information to people so that people can prepare themselves to minimize the damages. Social media acts as a big source of big data that easily generated by people's communication [35]. In this case, people of social media share disaster-related data and act as a sensor. Social media supply real-time data which can help to identify hotspot of disaster. It also facilitates to provide information related to the probability of damages, location, duration, distance and the extent of natural disasters.
2) Mitigation: Satellite images can be easily used for detecting upcoming adverse conditions related to climate change because of its relationship with geographical position. Many scholars developed various tools and systems such as satellite-based flood mapping, and the Moderate Resolution Imaging Spectroradiometer (MODIS) for effective monitoring disaster events [16]. Vulnerability and time series analysis are also helped to assess the possible risk of natural disasters. Risk assessment can be done by using user-generated data and predict the probable events of natural disasters. It can save huge damage such as people's livelihood assets, infrastructure, health, and other basic public service systems. Crowdsourcing system is also used for risk assessment particularly to the oil industry through assessing potential exposures like the smell, and smoke [26]. Mobile Metadata and call times can be a great source of big data and helpful for decision-makers to avoid any unexpected situation related to natural disasters [25]. It is also used for risk assessment and decision making. Flood related risk can be minimized by using spatial data and decision support system.

3) Response: Remote sensing imagery is the key tool to assess the damages caused by natural disasters. The requirement of imagery depends on the technique and process. The rapid initial assessment required large scale but lowresolution data of remote sensing which can help to recommend for proper initiative for the prioritized area [31]. $3 \mathrm{D}$ resolution imagery is necessary for assessing the damages of roads and buildings. Damages of people's shelter and transportation networks require high-resolution remote sensing imagery. It is also used for detecting open spaces of disaster-affected areas. Manned aircraft are also used for getting good imagery based on UAV based aerial system that can be easily used for detecting disaster-affected areas. Crowdsource is a vital tool for damage assessment [23]. It works based on the data provided by the people of the disaster affected areas to the platform of crowdsourcing.

Climate change affected areas faces many problems such as lack of communication, coordination of rescue team and lack of stakeholder awareness. These problems create a barrier in the post-disaster phase and reduce resilience. Disaster usually causes damages to the local resources that also create a barrier to post-disaster management [32]. These barriers can be easily solved by using big data analytics through assessment of the condition of affected areas and maximum utilization of limited resources. Mobile networks are hampered in some affected areas which also causes a barrier for post-disaster resilience but this problem can be solved by aerial ad hoc networks that ensure the connectivity among users of affected areas [47]. Big data analytics can play a vital role in climate change adaptation through identifying hotspot for an urgent response, coordination of people to move out from risks and identifying proper response method [48].

4) Recovery: Recovery phase deals to recover the people and their assets and bringing them to a normal condition which enhances resilience. Various kinds of infrastructure are 
necessary for making a proper plan for quick recovery such as information related to relief distribution, confirmation of safety, coordination of volunteer activities and logistic supply [32]. The damaged communication networks are required to recover and improve rapidly. Big data can help to improve regular as well as adaptive optimization for increasing infrastructure network as an essential part of disaster recovery [34]. Communication and adaptation mechanism can be done properly by utilizing limited resources under the approaches of big data. Satellite imagery may be a vital source of big data in the post-disaster stage. Climate change affected areas can be easily detected by remote sensing imagery. Recovery evaluation is easily done by using remote sensing data.

\section{CONCLUSION}

Climate change vulnerability is considered as a common challenge all over the world. The potential of big data can be a key approach to handle the adverse effect of climate change globally. Therefore, this study focuses to develop contextspecific adaptation strategy for enhancing climate change resilience by using big data technology. This study argues that resilience is a process of bounce back to the previous condition after facing any adverse effect. It also focuses on the integrated function of the adaptive, absorptive and transformative capacity of a social unit such as individual, community or state for facing any natural disaster. Big data technologies can show the information regarding upcoming issues, current issues and recovery stages of the adverse effect of climate change. It also argues that big data is a potential tool for policymakers, administrators, and related stakeholders to take necessary actions during and after disasters like an early warning system, weather forecasting, emergency evacuation, immediate responses, relief distribution, training need assessment and increasing trained individuals. For getting the maximum benefit from a big data approach for climate change resilience, this study suggests solving the related problems like challenges in data collection, analytics, infrastructure, gaps between human and technological capacity, ethical and political anomaly, poor coordination, privacy, and accuracy. This study recommends implementing proper infrastructure, technologies, tools and expertise for ensuring proper utilization of big data for climate resilience.

\section{REFERENCES}

[1] R. Pandey, S. K. Jha, J. M. Alatalo, K. M. Archie, and A. K. Gupta, "Sustainable livelihood framework-based indicators for assessing climate change vulnerability and adaptation for Himalayan communities," Ecol. Indic., vol. 79, pp. 338-346, 2017.

[2] S. A. P. Kumar, S. Bao, V. Singh, and J. Hallstrom, "Flooding disaster resilience information framework for smart and connected communities," J. Reliab. Intell. Environ., vol. 5, no. 1, pp. 3-15. 2019.

[3] B. Walker and D. Salt, "Practicing Resilience in Different Ways," in Resilience Practice, B. Walker and D. Salt, Eds. Washington, DC: Island Press/Center for Resource Economics, 2012, pp. 145-167.

[4] C. S. Holling, "Resilience and Stability of Ecological Systems," Annu. Rev. Ecol. Syst., vol. 4, no. 1, pp. 1-23, Nov. 1973.

[5] FAO, Analysing Resilience for Better Targeting and Action. Food and Agriculture Organization of the United Nations, Rome, Italy, 2016.

[6] C. Folke, "Resilience: The emergence of a perspective for socialecological systems analyses," Glob. Environ. Chang., vol. 16, no. 3, pp. 253-267, 2006.
[7] W. N. Adger, T. P. Hughes, C. Folke, S. R. Carpenter, and J. Rockstrom, "Social-Ecological Resilience to Coastal Disasters," Science (80)., vol. 309, no. 5737, pp. 1036-1039, Aug. 2005.

[8] C. Yang, G. Su, and J. Chen, "Using big data to enhance crisis response and disaster resilience for a smart city," in 2017 IEEE 2nd International Conference on Big Data Analysis, ICBDA 2017, 2017, pp. 504-507.

[9] K. Amjad and K. Almustafa, "Architecture Considerations for Big Data Management,” Int. J. Adv. Comput. Sci. Appl., vol. 7, no. 8, 2016.

[10] J. R. Ragini, P. M. R. Anand, and V. Bhaskar, "Big data analytics for disaster response and recovery through sentiment analysis," Int. J. Inf. Manage., vol. 42, no. May, pp. 13-24, Oct. 2018.

[11] H. Maryam, M. Ali, Q. Javaid, and M. Kamran, "A Survey on Smartphones Systems for Emergency Management (SPSEM)," Int. J. Adv. Comput. Sci. Appl., vol. 7, no. 6, pp. 301-311, 2016.

[12] L. Bizikova, P. Larkin, S. Mitchell, and R. Waldick, "An indicator set to track resilience to climate change in agriculture: A policy-maker's perspective," Land use policy, vol. 82, no. December 2018, pp. 444456, 2019.

[13] W. Hein et al., "Climate change and natural disasters: Government mitigation activities and public property demand response," Land use policy, vol. 82, no. August 2018, pp. 436-443, 2019.

[14] M. N. I. Sarker, Q. Cao, M. Wu, M. A. Hossin, G. M. Alam, and R. C. Shouse, "Vulnerability and livelihood resilience in the face of natural disaster: A critical conceptual review," Appl. Ecol. Environ. Res., vol. 17, no. 6, pp. 12769-12785, 2019.

[15] N. Agrawal, "Disaster Resilience," in Natural Disasters and Risk Management in Canada, N. Agrawal, Ed. Springer Science+Business Media B.V., 2018, pp. 147-191.

[16] M. Yu, C. Yang, and Y. Li, "Big data in natural disaster management: A review," Geosciences, vol. 8, no. 5, pp. 1-26, 2018.

[17] D. Moher et al., "Preferred reporting items for systematic reviews and meta-analyses: The PRISMA statement," PLoS Med., vol. 6, no. 7, 2009.

[18] J. Qadir, A. Ali, R. Rasool, A. Zwitter, A. Sathiaseelan, and J. Crowcroft, "Crisis analytics : big data-driven crisis response," J. Int. Humanit. Action, vol. 1, no. 12, pp. 1-21, 2016.

[19] B. Tomaszewski, M. Judex, J. Szarzynski, C. Radestock, and L. Wirkus, "Geographic Information Systems for Disaster Response: A Review," J. Homel. Secur. Emerg. Manag., vol. 12, no. 3, pp. 571-602, 2015.

[20] C. H. Park and E. W. Johnston, "An Event-Driven Lens for Bridging Formal Organizations and Informal Online Participation: How Policy Informatics Enables Just-in-Time Responses to Crises," in Policy Analytics, Modelling, and Informatics, vol. 25, 2018, pp. 343-361.

[21] M. Anbarasan et al., "Detection of flood disaster system based on IoT , big data and convolutional deep neural network," Comput. Commun., vol. 150, no. November 2019, pp. 150-157, 2020.

[22] A. Adeel et al., "A Survey on the Role of Wireless Sensor Networks and IoT in Disaster Management," in Geological Disaster Monitoring Based on Sensor Networks, T. S. Durrani, W. Wang, and S. M. Forbes, Eds. Singapore: Springer Singapore, 2019, pp. 57-66.

[23] R. I. Ogie, R. J. Clarke, H. Forehead, and P. Perez, "Crowdsourced social media data for disaster management: Lessons from the PetaJakarta.org project," Comput. Environ. Urban Syst., vol. 73, pp. 108-117, Jan. 2019.

[24] K. Ha, "Integrating the resources of Korean disaster management research via the Johari window," Eval. Program Plann., vol. 77, no. June, p. 101724, 2019.

[25] S. Shan, F. Zhao, Y. Wei, and M. Liu, "Disaster management 2.0: A real-time disaster damage assessment model based on mobile social media data-A case study of Weibo (Chinese Twitter)," Saf. Sci., vol. 115, pp. 393-413, Jun. 2019.

[26] K. M. Carley, M. Malik, P. M. Landwehr, J. Pfeffer, and M. Kowalchuck, "Crowd sourcing disaster management: The complex nature of Twitter usage in Padang Indonesia," Saf. Sci., vol. 90, no. May, pp. 48-61, Dec. 2016.

[27] M. Hyslop, "Comments on Standards in Information Security, Disaster Recovery, Business Continuity and Business Resilience," in Critical 
Information Infrastructures, no. January, Boston, MA: Springer US, 2007, pp. 94-144.

[28] R. I. I. Ogie, R. J. J. Clarke, H. Forehead, and P. Perez, "Crowdsourced social media data for disaster management: Lessons from the PetaJakarta.org project," Comput. Environ. Urban Syst., vol. 73, no. September 2018, pp. 108-117, Jan. 2019.

[29] N. Clark and F. Guiffault, "Seeing through the clouds: Processes and challenges for sharing geospatial data for disaster management in Haiti," Int. J. Disaster Risk Reduct., vol. 28, no. February, pp. 258-270, Jun. 2018.

[30] L. Resnyansky, "Social media data in the disaster context," Prometh. (United Kingdom), vol. 33, no. 2, pp. 187-212, 2015.

[31] T. Schempp, H. Zhang, A. Schmidt, M. Hong, and R. Akerkar, "A framework to integrate social media and authoritative data for disaster relief detection and distribution optimization," Int. J. Disaster Risk Reduct., vol. 39, no. April, p. 101143, Oct. 2019.

[32] A. Gupta, A. Deokar, L. Iyer, R. Sharda, and D. Schrader, "Big Data \& Analytics for Societal Impact: Recent Research and Trends," Inf. Syst. Front., vol. 20, no. 2, pp. 185-194, Apr. 2018.

[33] Z. Lv, X. Li, and K. K. R. Choo, "E-government multimedia big data platform for disaster management," Multimed. Tools Appl., vol. 77, no. 8, pp. 10077-10089, 2018.

[34] F. E. A. Horita, J. P. de Albuquerque, V. Marchezini, and E. M. Mendiondo, "Bridging the gap between decision-making and emerging big data sources: An application of a model-based framework to disaster management in Brazil," Decis. Support Syst., vol. 97, pp. 12-22, May 2017.

[35] M. Enenkel, S. M. Saenz, D. S. Dookie, L. Braman, N. Obradovich, and Y. Kryvasheyeu, "Social Media Data Analysis and Feedback for Advanced Disaster Risk Management," in Social Web in Emergency and Disaster Management 2018, 2018, pp. 1-5.

[36] S. B. Goldenberg et al., "The 2012 Triply Nested, High-Resolution Operational Version of the Hurricane Weather Research and Forecasting Model (HWRF): Track and Intensity Forecast Verifications," Weather Forecast., vol. 30, no. 3, pp. 710-729, Jun. 2015.

[37] T. Masood, E. So, and D. McFarlane, "Disaster Management Operations - Big Data Analytics to Resilient Supply Networks,” Dec. 2015.
[38] M. Di Felice, A. Trotta, L. Bedogni, K. R. Chowdhury, and L. Bononi, "Self-organizing aerial mesh networks for emergency communication," in 2014 IEEE 25th Annual International Symposium on Personal, Indoor, and Mobile Radio Communication (PIMRC), 2014, pp. 16311636.

[39] Z. Lu, G. Cao, and T. La Porta, "TeamPhone: Networking SmartPhones for Disaster Recovery," IEEE Trans. Mob. Comput., vol. 16, no. 12, pp. 3554-3567, Dec. 2017.

[40] D. Contreras, G. Forino, and T. Blaschke, "Measuring the progress of a recovery process after an earthquake: The case of L'aquila, Italy," Int. J. Disaster Risk Reduct., vol. 28, pp. 450-464, Jun. 2018.

[41] E. Alreshidi, "Smart Sustainable Agriculture (SSA) solution underpinned by Internet of Things (IoT) and Artificial Intelligence (AI)," Int. J. Adv. Comput. Sci. Appl., vol. 10, no. 5, pp. 93-102, 2019.

[42] A. Ahmad, R. Othman, M. Fauzan, and Q. M. Ilyas, "A semantic ontology for disaster trail management system," Int. J. Adv. Comput. Sci. Appl., vol. 10, no. 10, pp. 77-90, 2019.

[43] A. A. R. Madushanki, M. N. Halgamuge, W. A. H. S. Wirasagoda, and A. Syed, "Adoption of the Internet of Things (IoT) in agriculture and smart farming towards urban greening: A review," Int. J. Adv. Comput. Sci. Appl., vol. 10, no. 4, pp. 11-28, 2019.

[44] J. Cinnamon, S. K. Jones, and W. N. Adger, "Geoforum Evidence and future potential of mobile phone data for disease disaster management," Geoforum, vol. 75, pp. 253-264, 2016.

[45] J. R. Ragini, P. M. R. Anand, and V. Bhaskar, "International Journal of Information Management Big data analytics for disaster response and recovery through sentiment analysis," Int. J. Inf. Manage., vol. 42, no. September 2017, pp. 13-24, 2018.

[46] M. N. I. Sarker, M. Wu, G. M. Alam, and R. C. Shouse, "Livelihood resilience of riverine island dwellers in the face of natural disasters: Empirical evidence from Bangladesh," Land use policy, vol. 95, no. 2, p. 104599, Jun. 2020.

[47] V. Mali, M. Rao, and S. S. Mantha, "AHP driven GIS based emergency routing in disaster management," in Communications in Computer and Information Science, 2013, pp. 237-248.

[48] D. Kuroshima and T. Tian, "Detecting public sentiment of medicine by mining twitter data," Int. J. Adv. Comput. Sci. Appl., vol. 10, no. 10, pp. $1-5,2019$. 